\title{
THE EFFECT OF GIVING INTERMEDIATE AND INTERMEDIATE PLUS GUMBORO VACCINES AT THE AGE OF 21
}

MAAMON AL AMIR* and ANOUAR. ALOMAR ${ }^{* *}$

${ }^{*}$ Fact. of Vet. Med.-Albaath University.

${ }^{* *}$ Fact. of Vet. Med.-Albaath University.

E-Mail: mamonvet@hotmail.com

\section{ABSTRACT}

Received at: 3/8/2014

Accepted: 16/11/2014
This research aims to study the sera evaluation of the interference between maternal derived antibodies and IBD vaccines which are given lately. This research experienced a group of chicks taken from old aged breeders and another young ones. These were divided into groups, each one contains 30 chicks. These groups were given (Intermediate and Intermediate plus) IBD vaccines when They were 21 day. Before vaccination The MDA were examined as well as the levels of the antibodies which were produced from the vaccination. There were found that the late Gumboro vaccination would risk the Birds by Disease, There we also found That the intermediate plus vaccination would stimulate higher immune respone than the intermediate one, but it will cause a great damage in Bursa tissues.

Keywords: Intermediate, Intermediate plus, Gumboro vaccines, Age 21 day.

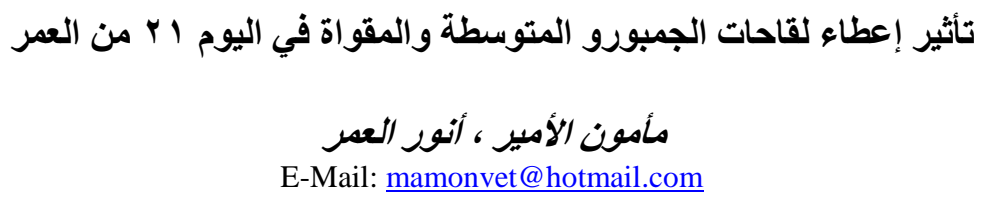

تهدف هذه الدر اسة إلى: تقييم مصلي للتداخلات بين المناعة الأمية ولقاحات الجمبورو المعطاة بعمر متأخر.

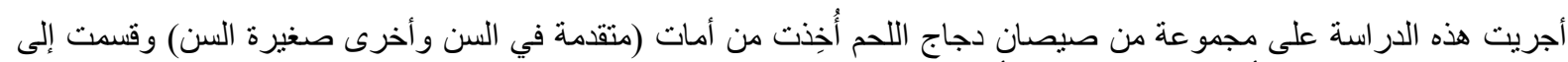

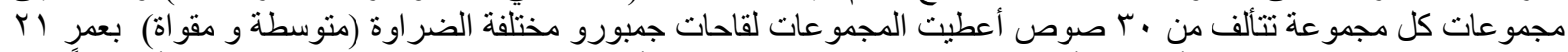

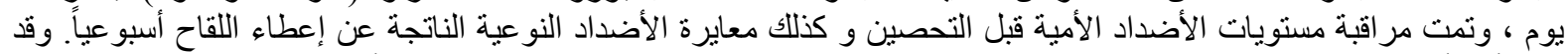

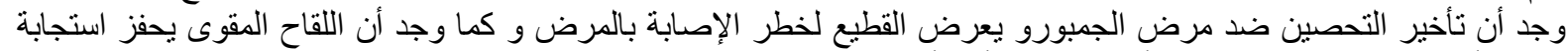

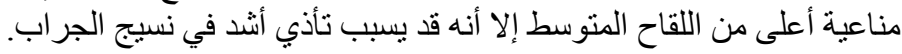

\section{INTRODUCTION \\ المقدمـة}

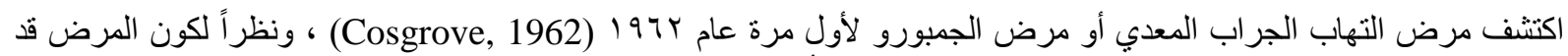

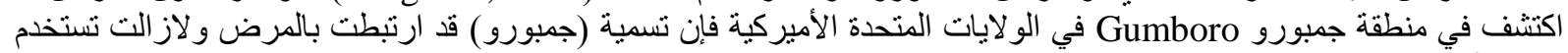
حتى الآن (Lukert and saif,1997). وقد سجلت إصابات بالمرض في العديد من دول العالم (Faragher, 1972).

ومنها الجمهورية العربية السورية حيث سُجِلَ المرض فيها مرض الجمبورو لأول مرة عام 997 (عبد العزيز ، 997 (19) ، حيث

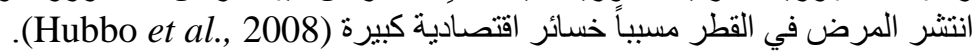

ينتمي العامل المسبب لمرض الجمبورو إلى عائلة بيرنا Carter et al., 2005) Birnaviridae)، وهي تضم ثلاثة أجناس رئيسة، وهي

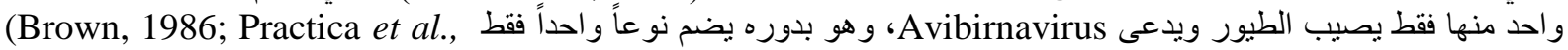
.2006; Pedro et al., 2008)

(Hirai and Shimakura, وهو من الفيروسات العارية ، ذو انتظام عشاري الوجوه ، يتراوح قطره ما بين

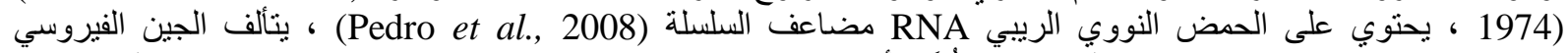

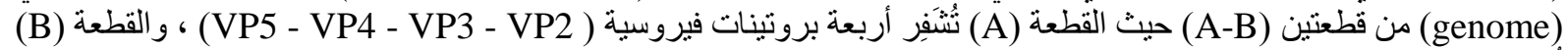

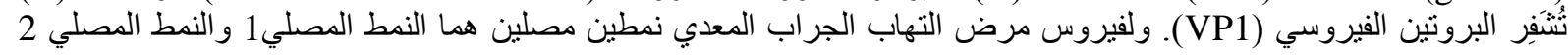




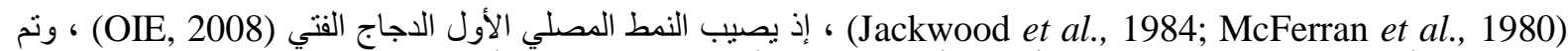
الكثف عن الأضداد النو عية للنمط المصلي الأول في أنو اع الطيور الأخرى مع عدم ظهور أعر اض المرل الفرض عليها، وتستخدِم لقاحات

مرض التهاب الجر اب المعدي ضد النمط الدصلي الأول (Dormitorio et al., 2007).

النمط المصلي الأول Serotype1 ، يصبب الدجاج ويسبب تثنيطاً للجهاز المناعي فيها ، ويضم ثلاث أنواع من العترات مختلفة في شدة الإمر اضية (Patricia et al., 2006):

آـ العترات الكلاسيكية Classic IBDV Strain: وتنتمي إليها العترة الكلاسيكية الضارية Virulent Classic IBDV التي تنتشر في أنحاء مختلفة العالم (Lojkic et al., 2008; OIE, 2008).

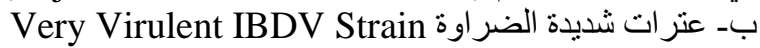

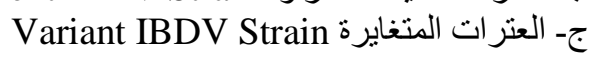

أما النمط المصلي الثناني Serotype فيُّد مسبباً للمرض في الدجاج الرومي (Ismail et al.,1988) ، وهو غير ممرض للاجاج. إذيُكن التفريق بين هذين النمطين المصليين باستخدام اختبار التعادل الفيروسي (لئي (Neutralization Test Virus).

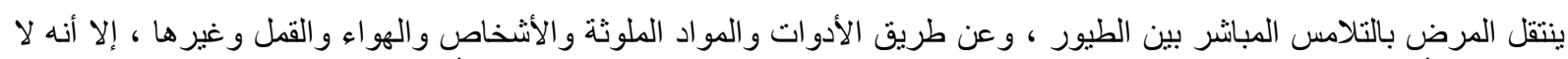

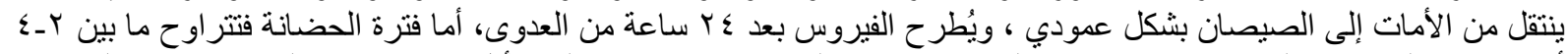

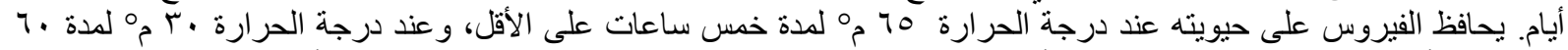

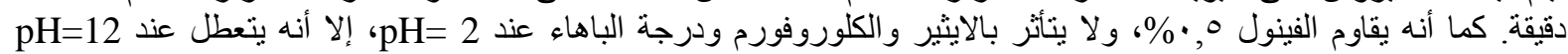

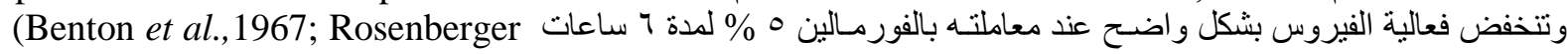
. et al., 1989)

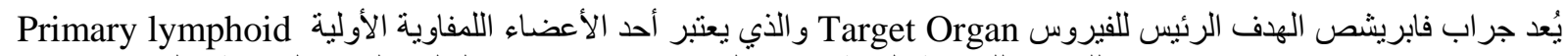

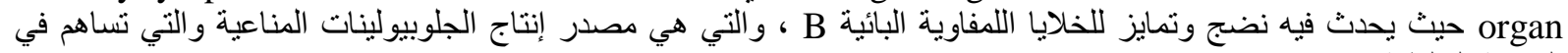
المناعة الخلطية ، (Tanimura and Sharma,1997).

إن خمج الطيور بعمر يوم واحد بـ IBDV يؤدي إلى قلة شديدة في IgG في المصل بشكل كامل ولكنه يزداد في الأسبوع الأول للخمج بينما تنخفض مستويات IgM معنوياً وبغض النظر عن وقت الخمج (Hirai et al., 1974).

(Dohms and يكون مسؤو لاً عن مضاعفات الإصابة بأخماج حقلية أخرى IBD إنتيط المناعي الناتج عن الإصابة بفيروس) .Saif,1984)

يتم السبطرة على المرض عن طريق تطبيق إجراءات التحصين والأمن الحيوي وتأمين مناعة كافية عند الطيور وهناك طريقتان

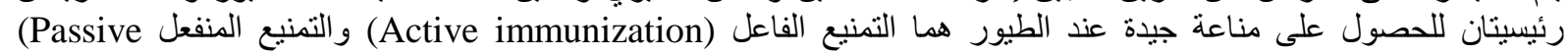
.(Tizard, 2004) immunization)

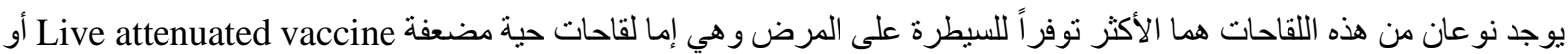

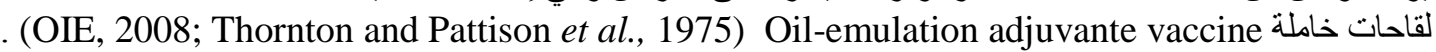

تحضر اللقاحات الحية من عترات حقلية للفيروس مضعفة على المز ارع الخلوية أو على أجنة بيض الدجاج وتختلف هذه اللقاحات فيما بينها تبعاً لضراوتها (لارجة إضعاف العترة الحقلية) فيمكن أن تكون اللقاحات ضعيفة Mild Vaccines، أو لقاحة التحات منوسطة

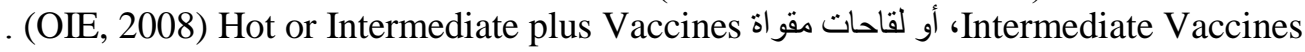

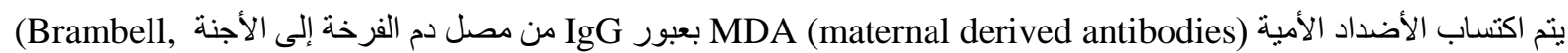

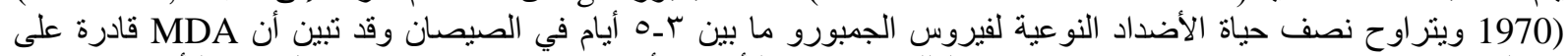

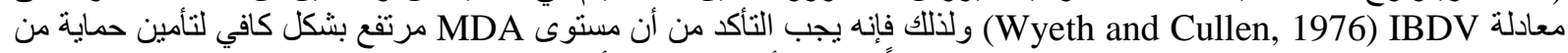

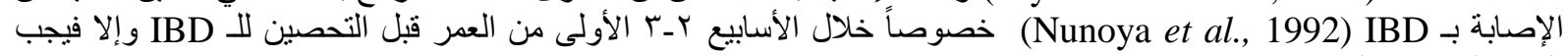

القيام بالتحصين المبكر.

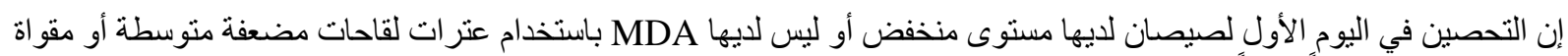

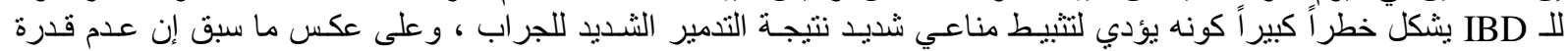

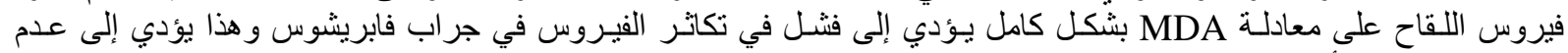

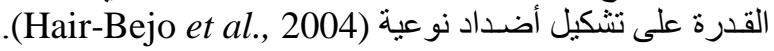


لقد وجد أنه هنالك العديد من القطعان التي أصيبت بالـ IBD قد حصنت بلقاح الجمبورو الحي عن طريق ماء الثرب وبأعمار تنتراوح

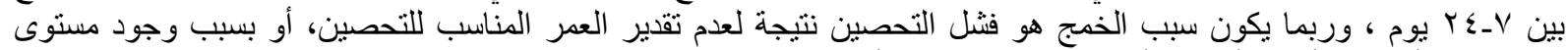
مرتفع من الأضداد الأمية ، أو الخطأ في طريقة التحصين، أو فوعة اللقاح المستخدم (Eterradossi and Saif, 2008).

وقد وجد أنه إذا حصنت الطيور قبل الوقت المناسب للتحصين بأكثر من يوم واحد فإن الاستجابة المناعية الخلطية تتأخر أو لا تلاحظ

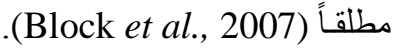

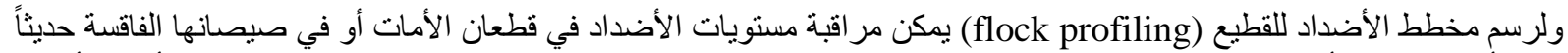
حيث أن ذللك يمكن أن يساعد في تحديد الوقت المناسب للتحصين (Eterradossi and Saif, 2008) ، مع الانتباه إلى أنها إذا أخذت الأن الأن

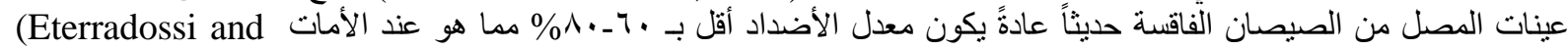

Saif, 2008)

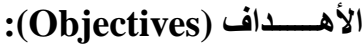

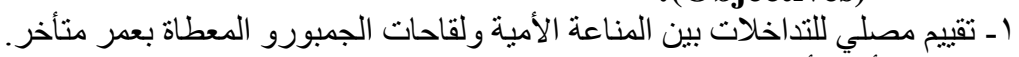

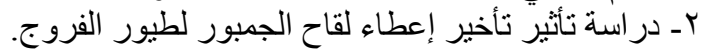

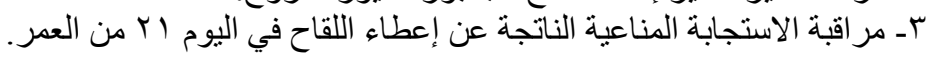

\section{MATERIALS and METHODS} مواد وطر ائق العمل

تم تربية طيور التجربة في حظيرة كلية الطب البيطري لجامعة البعث و أنجزت الاختبار ات أيضا في مخابر الكلية.

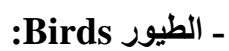
تم الحصول على صيصان بعمر يوم واحد من سلالة تجارية معروفة من مصدرين للأمات مختلفين في العمر. المصدر الأول: Group1 تتكون من O Vo صوص بعمر يوم واحد ، أخذت من أمات صغيرة العمر (عمر الأمات عند الحصول على

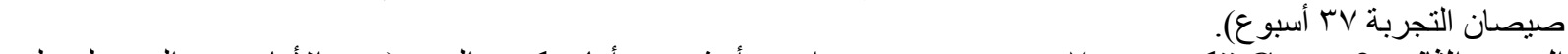
المصدر الثاني: Group2 تنكون من Vo صوص صوص بعمر يوم واحد ، أخذت من أمات كبيرة العمر (عمر الأمات عند الحصول على صبصان التجربة النية 00 أسبوع).

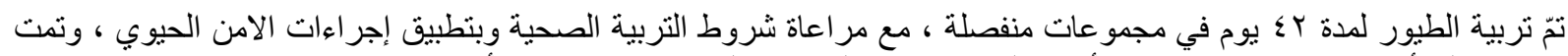

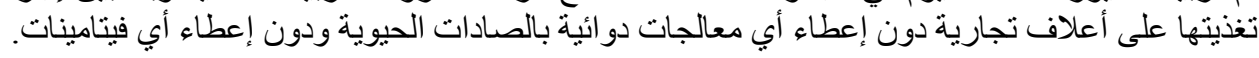

\section{ـ اللقاحات Vaccines

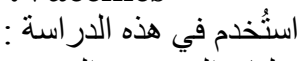

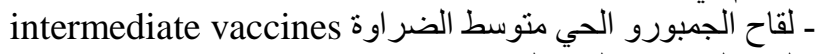 ـ لقاح الجمبورو الحي المقوى Intermediate plus vaacines}

Methods الطرق بلغ عدد الطيور في بداية التجربة ـ إصوص في اليوم الأول من العمر قسمت إلى مجموعات كما يلي :

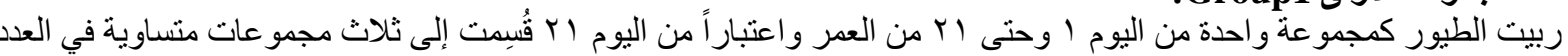

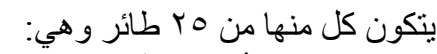

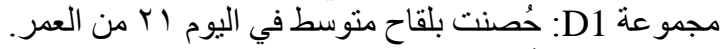

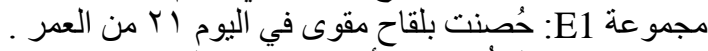
مجمو عة F1 : لم تُحصن و أبقيت كثَاهد سلبي.

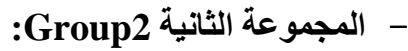

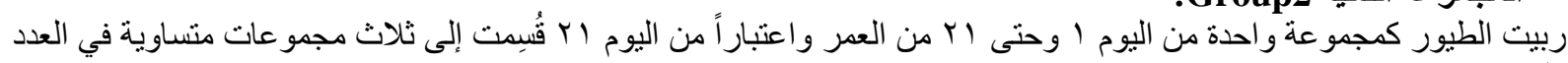

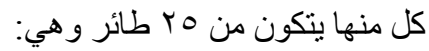

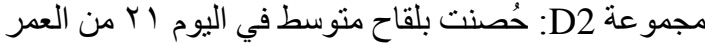

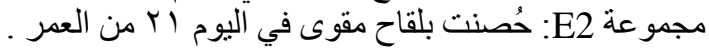




$$
\text { مجمو عة F2 : لم تُحصن و أبقيت كثاهد سلبي. }
$$

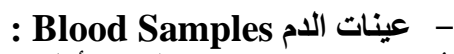

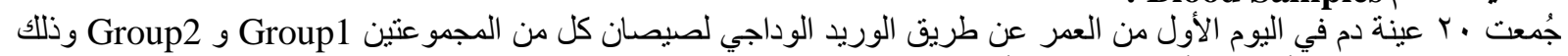
للكثف عن المستوى الأضداد الأمية في اليوم الأول.

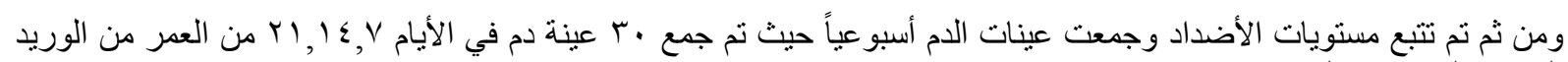

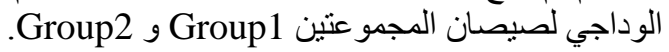

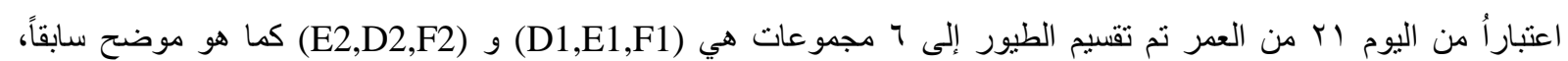

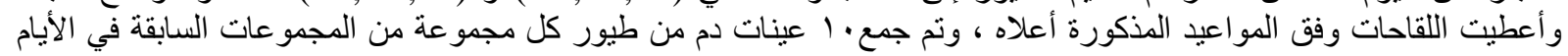

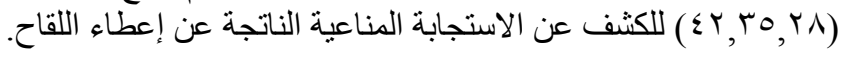

وضعت عينات الدم في أنابيب عقيمة بشكل مائل على سطح مستوي لتسريع عملية تجلط الدم و المساعدة في انفصال المصل ثم ثفلت

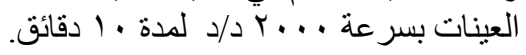

حفظت عينات المصل في أنابيب ابنذورف بدرجة حر ارة ـ. r درجة مئوية لتتم معايرة الأضداد لاحقاً.

طريقة التحصين Vaccination أعطي اللقاح عن طريق التقطير بالعين حيث تمت إماهة محتويات عبوة اللقاح المجف بالمذيب الخاص به وذللك حسب تعليمات الثركة

التقنيات المخبرية Laboratory Techniques:

المقايسة المناعية بالأنزيم المرتبط غير المباشرة Indirect Enzyme-Linked Immunosorbent Assay:

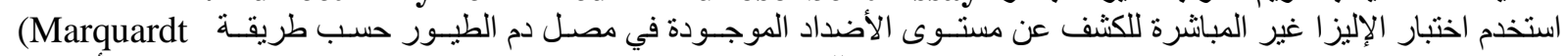
وذلك باستخدام مجموعتان نتخيصيتان من شركة et al.,1980; Rosenberger,1989; OIE, 2008)

.(Serial No.:09260-EE206)

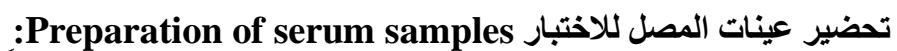

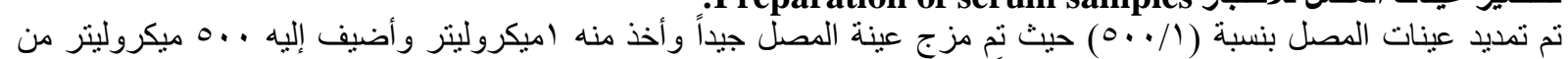
محلول التمديد Dilution Buffer ومزجت جيداً قبل توزيعها على أطباق الإليزا.

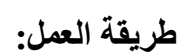

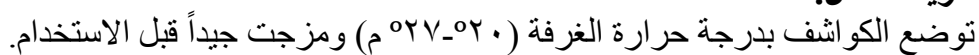

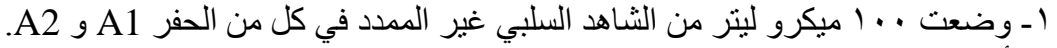

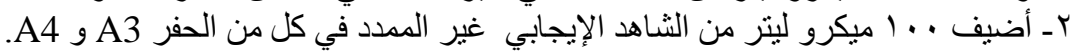

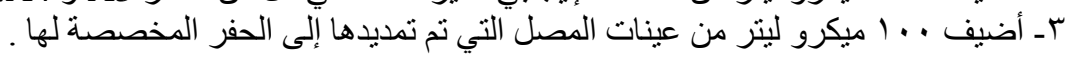

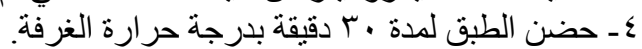

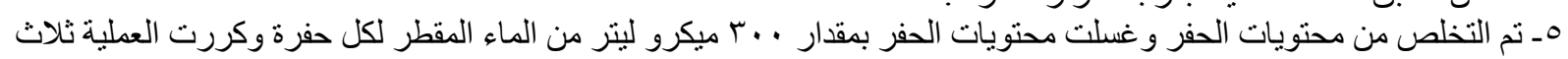

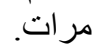

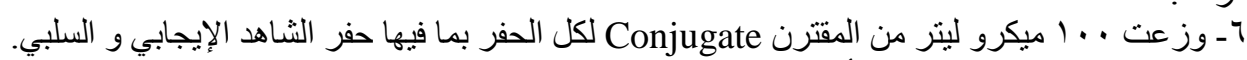

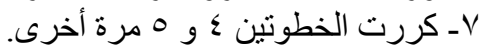

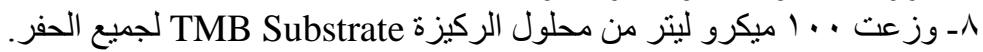

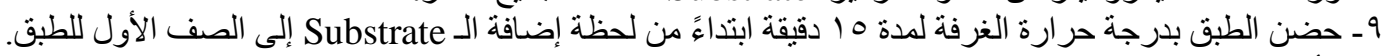

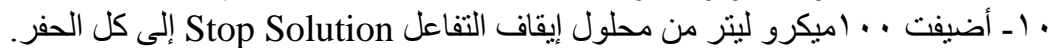

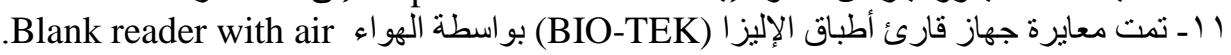

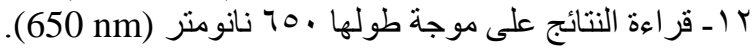

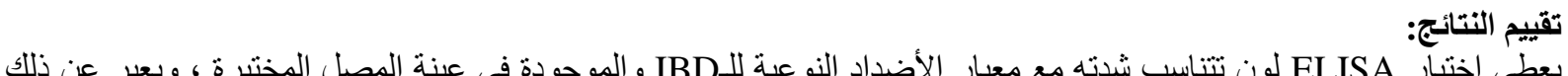

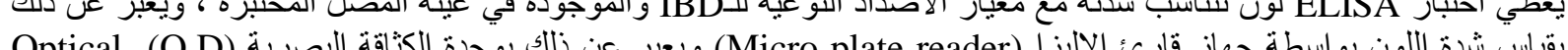

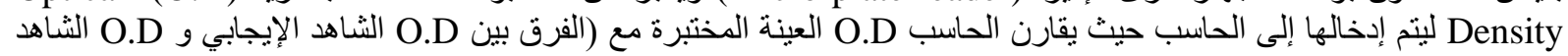

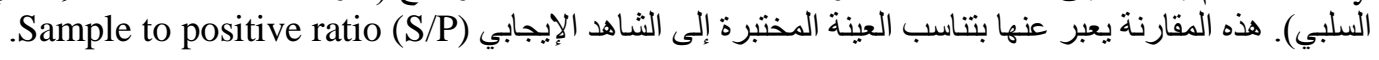


وحتى تكون نتائج العمل صحيحة يجب أن يكون الفرق بين متوسط الثناهد الإيجابي و متوسط الثاهد السلبي (PC (0.057)، و أن يكون منوسط امتصاصية الثناهد السلبي أقلى من (0.150).

وعندما تكون قيمة التناسب S/P للعينة المختبرة أقل أو يساوي (0.20) تعتبر العينة سلبية، وعندما تكون قيمة تتاسب S/P للعينة

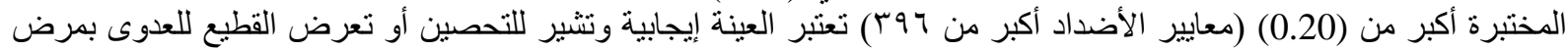

Negative control mean $(\mathrm{NC} \overline{\boldsymbol{X}})$

$\bar{x}_{\mathrm{NC}}=\frac{\text { Well } A 1 A(650)+\text { Well } A 2 A(650)}{2}$

Positive control mean $(\mathrm{PC} \overline{\boldsymbol{X}})$

$\mathrm{PC} \bar{X}=\frac{\text { Well } A 3 A(650)+\text { Well } A 4 A(650)}{2}$

$S / p$ ratio $S / p=\frac{\text { Sample Mean }- \text { NC } \bar{x}}{\mathrm{PC} \bar{x}-\mathrm{NC} \bar{x}}$

Titer - relates $S / p$ at a 1:500 dilution to an endpoint titer:

$\log _{10}$ Titer $=1.09\left(\log _{10} s / p\right)+3.36$

التحليل الإحصائي Statistical analysis:

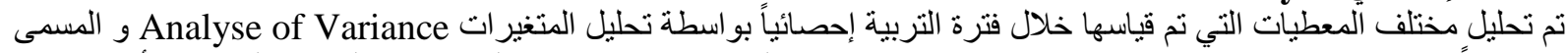
اختصاراً (ANOVA (Analysis OF Variance)، عندما تكون الفروق معنوية بين قيم المتوسطات الحسابية لمعايير الأضداد ، يتم

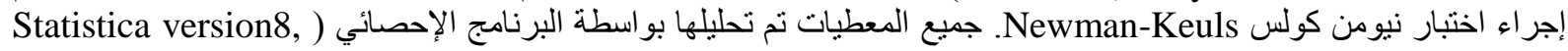
(Stat Soft 2008, USA

\section{RESULTS}

النتائسج

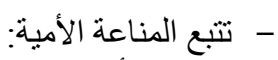

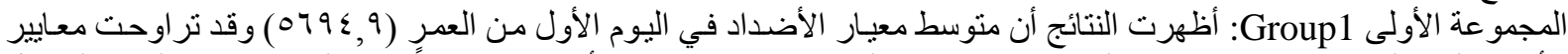

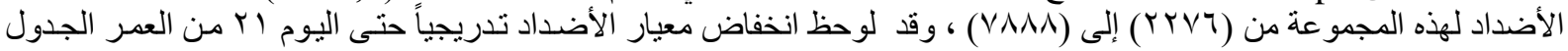

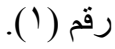

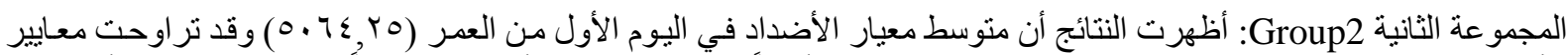

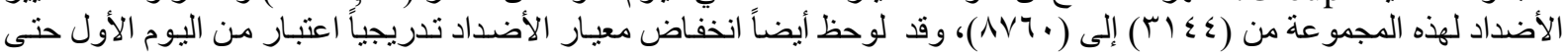

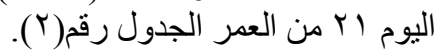

- - الاستجابات المناعية الناتجة عن التحصين:

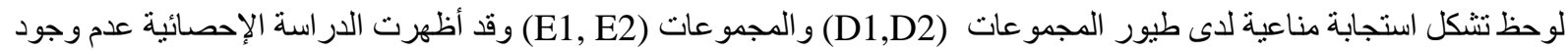

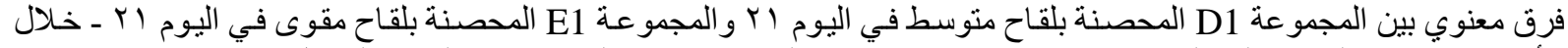

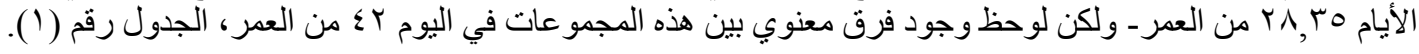

$$
\text { وقد كانت نتائج الدر اسة الإحصائية لدى المجموعتين (D2,E2) مشابهة لما سبق الجدول رقم (r). }
$$


Assiut Vet. Med. J. Vol. 60 No. 143 October 2014

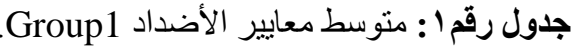

\begin{tabular}{|c|c|c|c|}
\hline العمر بالأيام & \multicolumn{3}{|c|}{ المجمو عة } \\
\hline 1 & \multicolumn{3}{|c|}{$\begin{array}{c}5694.9 \pm 292.99 \\
\mathrm{~N}=20\end{array}$} \\
\hline V & \multicolumn{3}{|c|}{$\begin{array}{c}2338.12 \pm 146.58 \\
\mathrm{~N}=30\end{array}$} \\
\hline $1 \varepsilon$ & \multicolumn{3}{|c|}{$\begin{array}{c}651.68 \pm 84.42 \\
\mathrm{~N}=30\end{array}$} \\
\hline r) & \multicolumn{3}{|c|}{$\begin{array}{c}234.57 \pm 40.66 \\
\mathrm{~N}=30\end{array}$} \\
\hline rA & $\begin{array}{c}\text { D1 المجموعة } \\
57.5 \pm 30.06^{\text {ns }} \\
\text { N=10 }\end{array}$ & $\begin{array}{c}\text { المجمو عة } 21.40 \pm 20.40^{\mathrm{ns}} \\
\text { N=10 }\end{array}$ & $\begin{array}{c}\text { F1 المجموعة } 5.50 \pm 19.33^{\text {ns }} \\
\text { N=10 }\end{array}$ \\
\hline To & $\begin{array}{c}\text { D1 المجمو عة } 1250.60 \pm 131.14^{a} \\
\text { N=10 }\end{array}$ & $\begin{array}{c}\text { المجموعة } 1390.10 \pm 264.42^{a} \\
\text { N=10 }\end{array}$ & $\begin{array}{c}\text { F1 المجموعة } \\
1.00 \pm 0.0{ }^{b} \\
\text { N=10 }\end{array}$ \\
\hline$\varepsilon r$ & $\begin{array}{c}\text { D1 المجمو عة } 1514.66 \pm 197.38^{b} \\
\text { N=10 }\end{array}$ & $\begin{array}{c}\text { E1 المجموعة } \\
2601.10 \pm 301.82^{a} \\
\text { N=10 }\end{array}$ & $\begin{array}{c}\text { المجمو عة } 1.00 \pm 0.00^{b} \\
\text { N=10 }\end{array}$ \\
\hline
\end{tabular}

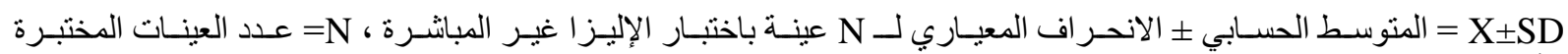

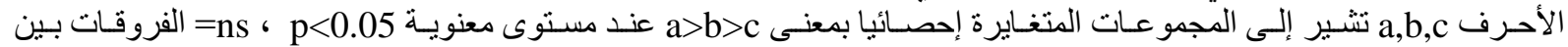
المتوسطات غير معنوية.

مجمو عة D1= حصنت بلقاح منو سط في اليوم الواحد و العشرين ، مجموعة E1= حصنت بلقاح مقوى في اليوم الو احد و العشرون من

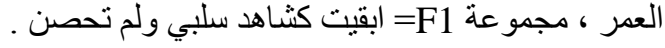

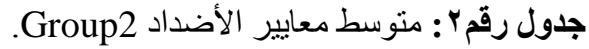

\begin{tabular}{|c|c|c|c|}
\hline \multirow{2}{*}{ العمر بالأيام } & \multicolumn{3}{|c|}{ المجمو عة } \\
\hline & \multicolumn{3}{|c|}{$\mathrm{X} \pm \mathrm{SD}$} \\
\hline 1 & \multicolumn{3}{|c|}{$\begin{array}{c}5064.25 \pm 336.71 \\
\mathrm{~N}=20\end{array}$} \\
\hline V & \multicolumn{3}{|c|}{$\begin{array}{c}1647.04 \pm 130.32 \\
\mathrm{~N}=30\end{array}$} \\
\hline $1 \varepsilon$ & \multicolumn{3}{|c|}{$\begin{array}{c}460.58 \pm 66.07^{\mathrm{ns}} \\
\mathrm{N}=30\end{array}$} \\
\hline rI & \multicolumn{3}{|c|}{$\begin{array}{c}256.30 \pm 57.76^{\mathrm{ns}} \\
\mathrm{N}=30\end{array}$} \\
\hline$r \wedge$ & $\begin{array}{c}\text { D2 المجمو عة } 1.00 \pm 0.00^{\mathrm{ns}} \\
\text { N=10 }\end{array}$ & $\begin{array}{c}\text { E2 المجموعة } \\
84.70 \pm 62.47^{\mathrm{ns}} \\
\mathrm{N}=10\end{array}$ & 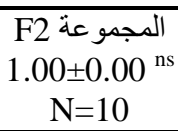 \\
\hline ro & $\begin{array}{c}\text { D2 المجموعة } 25.50 \\
1387.80 \pm 256.50 \\
\text { N=10 }\end{array}$ & 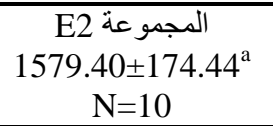 & $\begin{array}{c}\text { F2 المجمو عة b } \\
1.00 \pm 0.00 \\
\text { N=10 }\end{array}$ \\
\hline$\leq r$ & $\begin{array}{c}\text { D2 المجمو عة } 1322.25 \pm 123.67^{b} \\
\text { N=10 }\end{array}$ & $\begin{array}{c}\text { E2 المجموعة } \\
1717.40 \pm 312.85^{a} \\
N=10\end{array}$ & $\begin{array}{c}\text { المجمو عة c2 } \\
1.00 \pm 0.00^{c} \\
\text { N=10 }\end{array}$ \\
\hline
\end{tabular}

X+SD

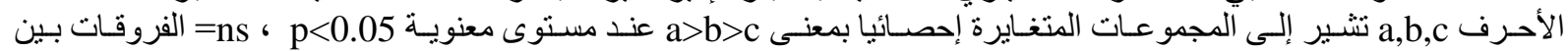
المتوسطات غير معنوية. مجمو عة D2= حصنت بلقاح منوسط فئل في اليوم الو احد و العشرين ، مجموعة E2= حصنت بلقاح مقوى في اليوم الو احد و العشرون من العمر ، مجمو عة F2= ابقيت كثاهد سلبي ولم تحصن. 


\section{DISCUSSION}

المناقشة

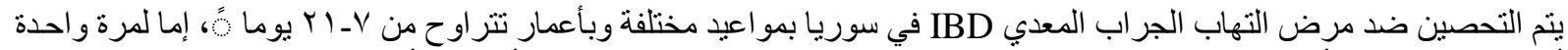

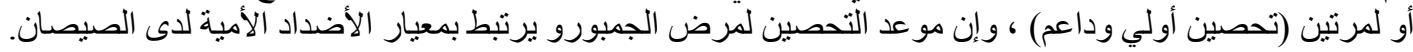

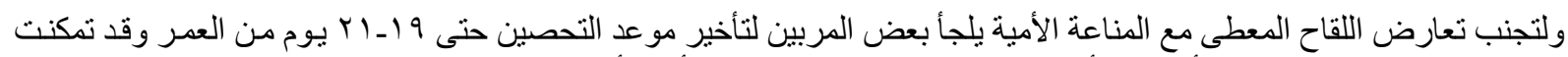

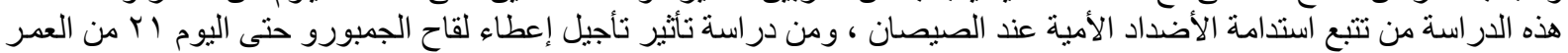
، ومن دراسة الفروقات في الاستجابات المناعية الناتجة عن اختلاف عترة اللقاح المستخدم.

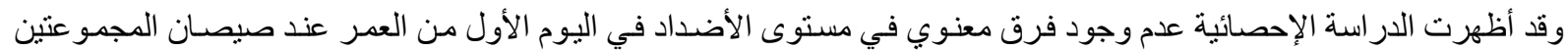

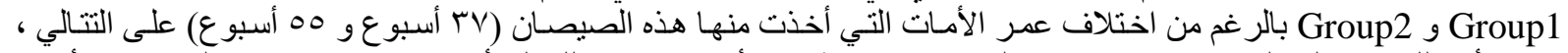

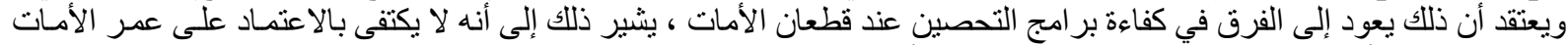

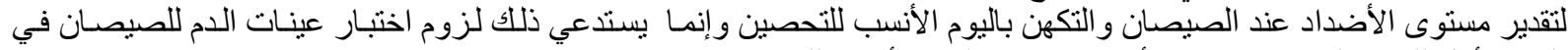
اليوم الأول للتربية لتحديد مستوى الأضداد وتقدير اليوم الأنسب للتحصين.

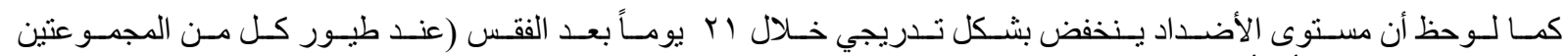
(Group1,Group2

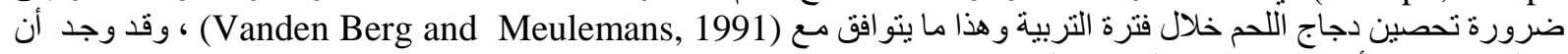
معدل انخفاض الأضداد هو تقريبا النصف كل ه. بـ يوم.

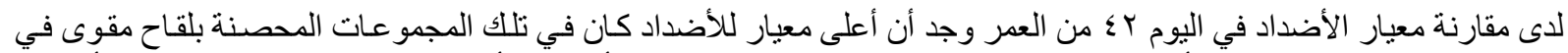

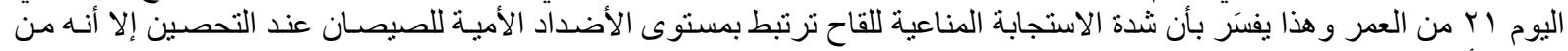

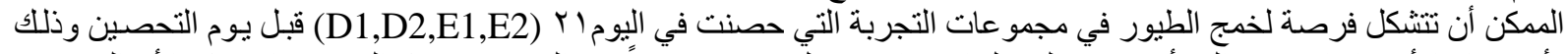

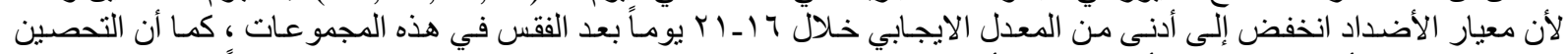

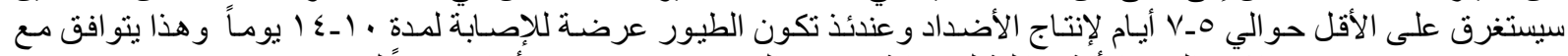

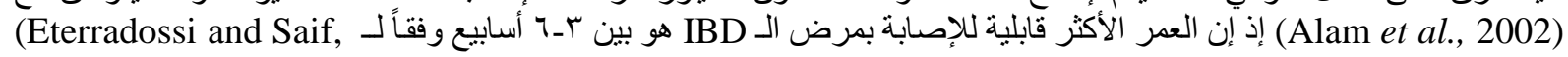

.2008)

\section{CONCLUSIONS and RECOMMENDATION الاستنتاجات و التوصيات}

\footnotetext{
. يرتبط مو عد التحصين لمرض الجمبورو بشكل أساسي بمستوى الأضداد الأمية عند الصيصان وبنصف عمر هذه الأضداد.

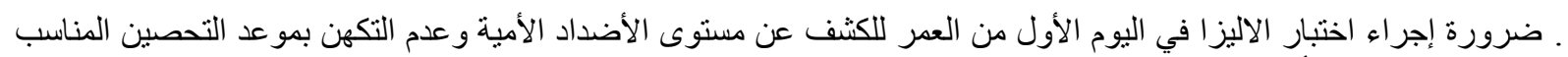
بالاعتماد على عمر الأمات فقط.

ـ إن تأخير التحصين حتى اليوم I ب من العمر (دون در اسة الحالة المناعية للطيور) قد يجعل القطيع معرض لخطر الإصابة بالمرض.

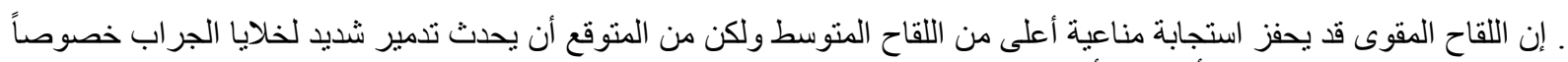
عند وجود مستوى متدني من الأضداد الأمية.

ـ توقيت التحصين ، ونوع اللقاح المستخدم، ومستوى MDA عند الصيصان ، وتحدي و إمر اضية الـ IBDV الحقلية هي عوامل هامة لتحديد فعالية وشكل برنامج التحصين لالتهاب الجراب المعدي.
}

\section{REFERENCES}

المراجـع

عبد العزيز ، فهيم (1997 (1)): دراسة الواقع الوبائي لمرض التهاب جراب فابريشيوس في مز ارع إع رعاية الفروج. مجلة جامعة تشرين

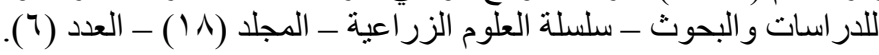

Alam, J.; Rahman, M.M.; Sil, B.K.; Khan, M.S.R. and Giasuddin Sarker, M.S.K. (2002): Effect of maternally derived antibody on vaccination against infectious bursal disease (Gumboro) with live vaccine in broiler, International Journal of Poultry Science, 1, 4, 98-101.

Benton, W.J.; Cover, MS. and Rosenberger, J.K. (1967): Studies on the transmission of the infectious bursal agent (IBA) of chickens. Avian DIS 11: 430- 438. 
Block, Hermann, Meyer-Block, Karen, Rebeski, Dierk E.; Scharr, Heike, de Wit, Sjaak, Rohn, Karl and Rautenschlein, Silke' (2007): A field study on the significance of vaccination against infectious bursal disease virus (IBDV) at the optimal time point in broiler flocks with maternally derived IBDV antibodies', Avian Pathology, 36: 5, 401-409.

Brambell, F.W.R. (1970): The transmission of passive immunity from mother to young. Frontiers of Biology, 18 : 20-41.

Brown, F. (1986): The classification and nomenclature of viruses: Summary of results of meetings of the International Committee on Taxonomy of Viruses in Sendai. Intervirology 25: 141-143.

Carter, G.R.; Wise, D.J. and Flores, E.F. (2005): Birnaviridae: In Virology. Cited by www.ivis.org.

Cosgrove, A.S. (1962): An apparently new disease of chicken avian-nephrosis. Avian Dis.6:385-389.

Dohms, JE. and Saif, YM. (1984): Criteria for evaluating immunosuppression. Avian Dis. 28:305-310.

DormitorioA, T.V.; GiambroneAC, J.J.; GuoA, K. and JackwoodB, D.J. (2007): Molecular and Phenotypic Characterization of Infectious Bursal Disease Virus Isolates. Avian Diseases 51(2): 597-600.

Eterradossi, N. and SAif, Y.M. (2008): Infectious Bursal Disease pp. 185-208 12 edition.

Faragher, J.T. (1972): Infectious bursal disease of chicken. Vet. Bull. 142: 361-396.

Hair-Bejo, M.; Ng, M.K. and Ng, H.Y. (2004): Day Old Vaccination Against Infectious Bursal Disease in Broiler Chickens Poultry Science 3 (2): 124-128, 2004.

Hirai, K. and Shimakura, S. (1974): Structure of infection bursal disease virus. J. Virol 14:957 -964.

Hirai, K., Shimakura, S.; Kawamoto, E.; Taguchi, F.; Kim, S.T.; Chang, C.N. and Iritani, Y. (1974): The immunodepressive effect of infectious bursal disease virus in chickens. Avian Dis 18: 50-57.

Hubbo, Kh.; Alomar, A. and Fadel, M. (2008): Prevalence of IBD Virus in some areas of Syria. Journal of ALBAATH University. Vol. 30- No: 8- pp 241-256.

Ismail, N.; Saif, Y. and Moorhead, P. (1988): Lack of pathogenicity of five serotype 2 infectious bursal disease virusin chickens. Avian Dis. 32: 757-759.

Jackwood, D.J.; Saif, Y.M.; Moorhead, P.D. and Bishop, G. (1984): Failure of two serotype II infectious bursal disease viruses to affect the humoral immune response of turkeys. Avian Dis 28: 100- 116.

Lojkic, I.Z. Biđin, B. Pokrc. (2008): Sequence Analysis of both Genome Segments of Three Croatian Infectious Bursal Disease Field Viruses. Avian Diseases Digest 3(3): e25-e25.

Lukert, P.D. and Saif, Y.M. (1997): Infectious bursal disease, p. 721-738. In B. W. Calnek, B. W. Barnes, C. W. Beard, L.R. McDougald, and Y.M. Saif (ed.), Diseases of poultry, 10th ed. Iowa State University Press, Ames.

Marquardt, W.; Johnson, R.B.; Odenwald, W.F. and Schlotthober, B.A. (1980): An indirect enzyme-linked immunosorbent assay (ELISA) for measuring antibodies in chickens infected with infectious bursal disease virus. Avian Dis. 24: 375-385.

McFerran, J.B.; McNulty, M.S.; McKillop, E.R.; Conner, T.J.; McCracken, R.M.; Collins, D.S. and Allan, G.M. (1980): Isolation and serological studies with infectious bursal disease viruses from fowl, turkey and duck: Demonstration of a second serotype. Avian Pathol 9: 395-404.

Nunoya, T.; Otaki, Y.; Tajima, M.; Hiraga, M. and Saito, T. (1992): Occurrence of acute infectious bursal disease with high mortality in Japan and pathogenicity of field isolates in SPF chicken. Avian Dis. 36: 597-609.

Office international des epizooties world organis animal health (2008): Manual of Standards for Diagnostic Tests and Vaccines.

Patricia, R.; Calderón, M.G.; Aguirre, S.; Periolo, O.; Torre, J. and Mattion, N. (2006): Characterization of Infectious Bursal Disease Viruses from Argentina. Avian Diseases 50(2): 245-251.

Pedro Villegas, A.; Hamoud, M.; Purvis, L.B. and Perozo, F. (2008): Infectious Bursal Disease Subunit Vaccination. Avian Diseases 52(4): 670-674.

Rosenberger (1989): Infectious bursal disease viruses. In: Isolation and idenrification of Avian pathogens, 3rd ed (Editorial committee: Purchase, H.C., Arp L.H Domermuth, C.H. and pearson, J.E) Kendall/Hunt publishing Company, Dubuque, Iowa, PP.165-166.

Tanimura, N. and Sharma, J.M. (1997): Appearance of T cells in the bursa of Fabricius and cecal tonsils during the acute phase of infectious bursal disease virus infection in chickens. Avian Dis. 41: 638-645.

Thornton, D.T. and Pattison, M. (1975): Comparison of vaccines against IBD. J. Comp. Pathol. 85: 597-610.

Tizard, I.R. (2004): Veterinary immunology (an introduction). Seventh Ed. Elsivier publishing company Philadilphia. USA.

Vanden Berg, T.P. and Meulemans, G. (1991): Acute infectious bursal disease in poultry; protection afforded y maternally- derived antibodies and interference with live vaccination. Avian Pathol. 20: 409-421.

Wyeth, P.J. and Cullen, G.A. (1976): Maternally derived antibody effect on susceptibility of chicks to infectious bursal disease. Avian Pathol., 5: 253-260. 